\title{
Measuring self-differentiation and academic commitment in University students: A case study of education and engineering students
}

\author{
Salomé Human-Vogel and Piet Rabe
}

\begin{abstract}
More than half of university students in South Africa leave university before they complete their studies. Factors associated with student drop out include poor schooling, lack of fluency in the language of instruction, poor financial support, and inadequate student support services. In the present study, we focus on the way meaningful commitment influences self-regulation, and we draw on the investment model of commitment to examine the hypothesis that commitment will be related to satisfaction, quality of alternatives, and investment size, and that self-differentiation will provide additional predictive power to commitment. Results indicate that satisfaction and self-differentiation only are significant predictors of level of academic commitment. Meaningful commitment is predicted by satisfaction, quality of alternatives, investment, and self-differentiation to a lesser extent. Investment size was associated significantly with self-regulatory behaviours such as setting learning goals, managing studies effectively, and spending more time on studies. The results are discussed in terms of the literature on commitment, self-differentiation, and academic achievement in higher education.
\end{abstract}

\section{Keywords}

Academic achievement, commitment, higher education, investment, satisfaction, selfdifferentiation

In 2011, student enrolment at South African universities comprised 938,201 undergraduate and postgraduate students, which represents about $18 \%$ of all young adults between the ages of 20 and 24 years (Council on Higher Education, 2013). In 2011, there were 164,939 students enrolled in

Department of Educational Psychology, University of Pretoria, South Africa

Corresponding author:

Salomé Human-Vogel, Department of Educational Psychology, Room 2-56, All Purpose Building, University of Pretoria, Pretoria, 0002, South Africa.

Email: salome.humanvogel@up.ac.za 
education, and about a 100,000 more in Science, Engineering, and Technology (SET). Of these students, 54\% who had enrolled for university studies for the first time in 2006 dropped out of higher education, suggesting that only about $10 \%$ of young South African adults eventually obtain an undergraduate or postgraduate qualification. In the present study, we take a self-regulation perspective on academic commitment and examine whether self-differentiation can predict commitment over and above satisfaction, quality of alternatives, and investment.

Several factors put students at risk for dropping out of higher education, such as poor schooling, lack of fluency in the language of instruction, poor financial support, and inadequate student support services (Strydom, Basson, \& Mentz, 2012). These factors impose external constraints on students' ability to complete their studies, but they do not necessarily impact on students' personal commitment to their studies, as it is quite conceivable that a student may have a strong commitment to completing their studies but not have the resources to finance their studies.

In the present study, we apply the investment model of commitment (Rusbult, Martz, \& Agnew, 1998) to the study of academic commitment. Developed originally to study commitment in romantic relationships, the investment model of commitment is based on interdependence theory with the central hypothesis that the decision to stay or leave a relationship will be determined by certain antecedents of commitment, that is, the satisfaction that an individual derives from the relationships, the size of the investment they have made, and the availability of better quality of alternatives to the relationship (Rusbult et al., 1998). However, the extent to which people derive satisfaction from their pursuits, the resources they invest, and whether they think better alternatives exist has relevance in many contexts other than interpersonal relationships. So, despite a tradition steeped in the study of romantic relationships, the investment model has nevertheless proven to be portable to the study of academic success (Kluger \& Koslowsky, 1988), and college student attrition (Geyer, Brannon, \& Shearon, 1987). Le and Agnew (2003) conducted a meta-analysis of investment model studies spanning over 20 years in various contexts and concluded that the investment model is not strictly an interpersonal theory, but can - and should - be extended to a wide range of noninterpersonal domains to assist in identifying the outer bounds of the model's applicability.

The reported diminished predictive utility of the investment model in non-interpersonal contexts (Le \& Agnew, 2003) suggests factors other than satisfaction, alternatives, and investment may predict commitment. In academic contexts, the most prominent theoretical frameworks that explain why students fail to attain educational outcomes include self-regulation (Bjork, Dunlosky, \& Kornell, 2013) and student engagement (Finn \& Zimmer, 2012). Self-regulation theories typically emphasise goal-oriented aspects of behaviour, while student engagement frameworks focus on the behavioural indicators associated with academic achievement such as time spent on tasks and quality of effort. It is useful to briefly consider commitment in relation to self-regulation, especially because we assume that people regulate their behaviour within the constraints of the commitments they have made (Human-Vogel, 2008, 2013). Lord, Diefendorff, and Schmidt (2010) propose four levels of abstraction in self-regulation that can explain how identity-relevant commitments can regulate behaviour. Lord et al. (2010) describe self-regulatory processes as occurring on different levels of abstraction and cycle times, namely, (1) micro-level, (2) low level, (3) intermediate level, and (4) high levels of abstraction. Self-regulatory behaviours include conscious and unconscious processes at the different levels, which run concurrently, with higher levels of selfregulation imposing constraints on lower levels. The micro-level refers to the physiological processes and resources that form the physical foundation of behaviour, and which occur largely unconsciously. Low level self-regulation refers to integrated task behaviours that span several seconds and are driven by schemas and scripts. The intermediate level of self-regulation, spanning minutes to days, implies conscious choices with the focus on achievement tasks that requires goal commitment. High level self-regulation spans months to years and is self-focused. 
We suggest that the levels of self-regulation reflect qualitatively different types of commitment that we describe as (1) physiological commitment (micro-level), (2) task commitment (low level task behaviours), (3) goal commitment (intermediate level), and (4) identity-related commitment (high level). Within the framework, we recognise that identity-related commitment - associated with high level self-regulation - imposes constraints on lower level self-regulatory processes that run concurrently and autonomously, and which are activated through cognitive schemas and behavioural scripts. This is why the 'commitment' to complete a particular task such as an assignment (that occurs on a low level) is qualitatively different from the 'commitment' to be a responsible person (at a high level). To illustrate, the commitment to a self that is known and experienced as 'responsible' will first influence the types of goals people select and commit to. To achieve goals, certain cognitive schemas associated with responsible behaviour may be activated over other schemas, which will in turn activate or prime behavioural scripts on lower levels that contain a repertoire of 'responsible' behaviours. Of course, completing an assignment can also occur in the absence of the belief that one is responsible, and as such would not reflect commitment per se. Students can complete tasks because they perceive no choice in the matter, that is, out of obligation to an external constraint. Thus, identity-level commitments impose internal constraints on the regulation of behaviour, while lower level commitments will be associated with external constraints on behaviour. Thus, we argue that, in the absence of identity-level commitments, goal and task commitments align better with the literature on academic engagement (Krause \& Coates, 2008) than commitment. Although we do not test the hypothesis in the present study, we think that the line of reasoning we present here is also consistent with contemporary thinking on human motivation and that identity-level commitment is likely to be associated with integrated regulation styles rather than external or introjected regulation styles (Niemiec \& Ryan, 2009).

In the present study, we focus on identity-level self-regulation where identity constructs, or possible selves, create constraints on lower levels of self-regulation. In our opinion, while the investment model of commitment (Rusbult et al., 1998) purports to measure long-term commitment, the model does not adequately distinguish between the various levels of commitment. We think it can be useful therefore to examine whether identity can add predictive value to the level of commitment. We argue, for example, that only high level, identity-relevant commitments will be experienced as meaningful, whereas intermediate level goal-oriented commitments can be experienced as satisfactory, but not necessarily meaningful. The difference essentially concerns the motivation to maintain a commitment as a means of achieving a goal that can lead to satisfaction (goal commitment), or because it is a way of expressing the self (identity-relevant commitment). This distinction is important because it reflects different traditions in the literature on wellbeing that concern hedonic and eudaimonic differences in the way researchers view wellbeing (Deci \& Ryan, 2008). People sometimes engage in relationships, and academic learning, because it is meaningful to them (which implies satisfaction), or simply as a source of satisfaction (but not necessarily meaning). The implication of this analysis would be that identity-relevant commitments would be experienced as meaningful and have more influence on self-regulatory behaviour, by implication of the investment of resources, and would be more stable over time. Of course, identity-relevant commitments assume a degree of self-knowledge and self-awareness, and the propensity to choose goals to be consistent with one's identity, which is what committed students seem to do (Human-Vogel, 2008).

In the present study, we conceptualised identity-relevant knowledge as objective selfknowledge (Human-Vogel, 2013), and the ability to perceive one's self as distinct from others, described by Skowron and Friedlander's (1998) construct of self-differentiation. A high level of self-differentiation as used in the present study refers to the ability to perceive oneself as autonomous, the ability to make rational decisions, and low emotional reactivity. The ability to perceive 
a rational and distinct self does not assume that the self is independent only, but also includes perceptions of the self as independent, interdependent, or collective (Sedikides, Gaertner, Luke, O'Mara, \& Gebauer, 2013). Self-differentiation involves the ability to achieve an autonomous self, which implies the ability to choose and endorse one's own actions (Skowron, Holmes, \& Sabatelli, 2003), which is consistent with the motivational theory where autonomy implies the capacity to make and endorse one's own choices (Deci \& Ryan, 2008).

Drawing on the Rusbult et al. (1998) model, we conceptualised the level of students' academic commitment as long-term persistence with their studies (level of commitment), and determined by the level of satisfaction they derive from their studies, the investments they make in their studies, as well as their perception of the desirability of alternatives available to studying. In addition, we formulated meaningful commitment as the extent to which commitments were experienced as reflective of the self and consistent with self-expression. Our primary objective was to examine the relationship between academic commitment and self-differentiation, with a view to test the hypothesis that self-differentiation would predict level and meaningfulness of academic commitment over and above satisfaction, quality of alternatives, and investment. This hypothesis rests on our theory that identity-level constructs can provide additional explanatory power to understanding how commitments may impose constraints on the self-regulation of behaviour. Our second objective was to examine whether commitment in an academic context would be associated with low level selfregulatory behaviours such as setting learning goals, and managing time and studies effectively.

\section{Method}

\section{Participants}

Participants were 259 university students (52\% female) from the Education (47\%) and Engineering (53\%) faculties, distributed across the second year of study (213 students), third year (41 students), and fourth year and beyond ( 3 students). Two students did not indicate the year of study. Of the participants, 123 were Afrikaans-speaking, 82 were English speaking, 45 reported an African language as their home language, and 9 students indicated another language. We did not collect racial or social-class information. Most of the participants ( 245 students) said they felt supported by their family, and approximately half of the participants (122 students) indicated they lived in a residence or commune.

\section{Instruments}

Participants completed an anonymous questionnaire consisting of demographic information, the Differentiation of Self Inventory - Revised (DSI-R; Skowron \& Friedlander, 1998), and the Academic Commitment Scale (ACS), which we developed by adapting items from the Rusbult et al. (1998) investment model of commitment scale to suit the academic context. Adaptations required slight changes to the wording of items (consistent with other adaptations reported in the literature, see Geyer et al., 1987) so that academic studies, and not a personal relationship, were the object of commitment. We also created additional items to measure meaningful commitment in an academic context, which we operationalised as identity-level commitment reflecting the extent to which commitment in an academic context allows the participant to express, and feel supported in expressing, their identity. Commitment items were rated on a 6-point Likert-type scale $(1=$ strongly disagree, $2=$ disagree, $3=$ slightly disagree, $4=$ slightly agree, $5=$ agree, $6=$ strongly agree). Selfdifferentiation items were also rated on a 6-point Likert-type scale with descriptors provided for only the endpoints of the scale $(1=$ not at all true of me and $6=$ very true of $m e)$. 


\section{Procedure}

Using a one-stage random cluster sampling method, we randomly sampled university undergraduate modules (clusters) and approached students for participation in those modules. In each case, permission to collect data was obtained from the Dean of the Faculty, as well as the Head of Department before lecturers was approached. Data were collected anonymously and students received no benefit or incentives for participating in the study.

\section{Ethical considerations}

The study received ethical clearance from the ethics committee of the University of Pretoria.

\section{Statistical analysis}

We conducted reliability and factor analyses (maximum-likelihood estimation with promax rotation) and, as recommended by De Vellis (2012), used multiple indices (Kaiser criterion, Cattell scree plot, parallel analysis) to test the extent to which the data from the ACS and the DSI-R converge to create a stable solution that fitted the assumed theoretical model. As a result of the factor analysis and reliability analysis, we created composite scores for the ACS, which reflected a good fit for the adapted investment model of commitment (root mean square error of approximation $[\mathrm{RMSEA}]=0.0567$; chi-square $=585.77, d f=320, p=.000)$. For the DSI-R, a three-factor solution was accepted with a good fit to the data $(\mathrm{RMSEA}=0.0576$; chi-square $=815.73, d f=462, p=.000)$. A total score and composite scores were therefore created as recommended in Skowron and Friedlander (1998) for the I-position ( $\alpha=.72, n=11$ items), Emotional Reactivity $(\alpha=.86, n=11$ items), and Emotional Cut-off ( $\alpha=.84, n=12$ items) scales. The Fusion With Others subscale was omitted from further analysis because items from that scale were distributed across all the other subscales and therefore were not conceptually clear enough to be measured reliably. The composite items for the ACS appear in Appendix 1.

For the ACS, five items $(\alpha=.84)$ assessed participants' level of commitment, which were presented in terms of the likelihood that they were determined to persist until finished as opposed to giving up with their studies. Eight items $(\alpha=.90)$ assessed participants' satisfaction with their studies. Five items $(\alpha=.90)$ assessed participants' level of investment in their studies, represented as the time and effort they put into their studies. Only three items $(\alpha=.68)$ assessed participants' perceptions of alternatives to studying, that is, whether they would rather do something else other than study, which affected the reliability of the scale adversely. Nine items $(\alpha=.91)$ assessed meaningfulness of participants' commitments, presented as the extent to which participants felt their commitment to their studies shaped their identity and permitted them to express their identity. In addition to the ACS and DSI-R, specific items were included to assess low level self-regulatory behaviours such as whether participants set learning goals for themselves, whether they were working towards life goals, whether they felt they manage their studies effectively, and whether they felt supported by their families. Participants also reported how much time they spend per day on average on their studies (0-60 min, 60-120 min, $120 \mathrm{~min}$ or more) and whether they had a part-time job.

\section{Results}

We used the composite scores for calculating the Pearson correlations for the ACS and DSI-R scales, and the outcome behaviours were used to see whether significant differences in the means on subscales were associated with outcome behaviours (Table 1). 
Table I. Correlations of academic commitment subscales.

\begin{tabular}{|c|c|c|c|c|c|}
\hline & SAT & QUAL & INVEST & MEANING & LEVEL \\
\hline Satisfaction (SAT) & - & $-.418 * *$ & $.542^{* *}$ & $.675^{* *}$ & $.515^{* *}$ \\
\hline $\begin{array}{l}\text { Quality of alternatives } \\
\text { (QUAL) }\end{array}$ & & - & $-.290 * *$ & $-.467^{* *}$ & $-.183^{* *}$ \\
\hline Investment (INVEST) & & & - & $.555^{* *}$ & $.273 * *$ \\
\hline Meaningfulness (MEAN) & & & & & $.237^{* *}$ \\
\hline $\begin{array}{l}\text { Level of commitment } \\
\text { (LEVEL) }\end{array}$ & & & & & - \\
\hline
\end{tabular}

$* * p=.000$.

Table 2. The bases of commitment and self-differentiation predicting level of commitment.

\begin{tabular}{llllllll}
\hline & $\beta$ & $t$ & $P$ & $R^{2}$ & $F$ & df & $p$ \\
\hline Model & & & & .271 & 20.72 & 4 & .000 \\
Satisfaction & .489 & 6.872 & .000 & & & & \\
Quality of alternatives & .055 & 0.869 & .386 & & & & \\
Investment & .005 & 0.074 & .941 & & & & \\
Self-differentiation & .130 & 2.183 & .030 & & & & \\
\hline
\end{tabular}

Predictor: level of commitment.

\section{Objective I: relationship between academic commitment and self-differentiation}

We hypothesised that commitment in an academic context should be positively associated with self-differentiation if commitment reflects an identity-level self-regulatory process. To achieve this objective, we first tested the investment model of commitment in an academic context by regressing the three bases of commitment, namely, satisfaction, investment, and quality of alternatives on level of commitment, and then, we regressed the three bases of commitment on the meaningfulness of commitments as a measure of the extent to which satisfaction, alternatives, investment, and selfdifferentiation may predict identity-level commitment (Table 2).

Correlations were in the expected directions and supported the theoretical assumptions of the investment model of commitment in an academic context. The weak, but significant correlations of the Quality of Alternatives subscale are probably related to the length of the scale (3 items). The correlations in the expected directions of the Meaningfulness subscale with the existing investment model subscales confirmed the theoretical soundness of the new meaningfulness scale. Next, we calculated a composite DSI-R score reflecting self-differentiation, and we specified a first-order hierarchical multiple linear regression model to test the hypothesis that a differentiated sense of self would predict level of commitment in addition to satisfaction, quality of alternatives, and investment. The variance inflation factor (VIF index) varied between 1.08 and 1.56, indicating that multicollinearity among the independent variables, despite significant correlations between them, did not influence the regression model unduly (Mendenhall \& Sincich, 2003).

Satisfaction was a robust predictor of student's level of commitment in an academic context $(\beta=.489, p=.000)$, and self-differentiation also added predictive power to the model $(\beta=.130, p=.030)$. Contrary to what we expected, quality of alternatives and investment did not emerge as predictors of level of commitment in an academic context. Next, we regressed satisfaction, quality of alternatives, investment, and self-differentiation on meaningful commitment as the dependent variable (Table 3 ). 
Table 3. The bases of commitment and self-differentiation predicting meaningful commitment.

\begin{tabular}{lrrrrrrr}
\hline & $\beta$ & \multicolumn{1}{c}{$t$} & $P$ & $R^{2}$ & $F$ & $d f$ & $P$ \\
\hline Model & & & & .544 & 66.69 & 4 & .000 \\
Satisfaction & .473 & 8.337 & .000 & & & & \\
Quality of alternatives & -.195 & -3.880 & .000 & & & & \\
Investment & .277 & 5.180 & .000 & & & & \\
Self-differentiation & -.097 & -2.060 & .041 & & & & \\
\hline
\end{tabular}

Predictor: meaningful commitment.

Satisfaction was again a robust predictor of meaningful commitment $(\beta=.473, p=.000)$. Contrary to the model in which level of commitment was the dependent variable, quality of alternatives was a significant predictor of meaningful commitment $(\beta=-.195, p=.000)$, as was investment $(\beta=.277, p=.000)$, whereas the predictive power of self-differentiation was barely significant, and severely diminished $(\beta=-.097, p=.041)$.

\section{Objective 2: is commitment in an academic context associated with self-regulatory behaviours such as learning goals, study management, and time spent on studies}

Using Levene's test for equality of variance, and the independent samples $t$-test for equality of means, we examined whether students who set learning goals and felt they managed their studies effectively would differ significantly in levels of commitment and self-differentiation from those who did not set learning goals or who felt they were not managing their studies successfully. Overall, education students felt more satisfied with their studies than engineering students $(t=3.365, d f=255, p=.001)$, and also reported greater investment in their studies $(t=2.599$, $d f=255, p=.01)$. Considering the overall student group, those who set learning goals were more likely to report meaningful commitment $(t=2.168, d f=247, p=.031)$, higher satisfaction with their studies $(t=4.097, d f=255, p=.000)$, invest more time and effort $(t=3.388, d f=255, p=.001)$, and less likely to see better alternatives than studying $(t=-3.937, d f=252, p=.000)$. Interestingly, whether students set learning goals did not matter in terms of their overall level of commitment or self-differentiation, but students who felt supported by their families reported significantly higher levels of self-differentiation $(t=2.371, d f=235, p=.019)$ than those who felt unsupported.

If students felt they managed their studies effectively, they were likely to report higher selfdifferentiation $(t=3.852, d f=235, p=.000)$, more satisfaction $(t=4.721, d f=255, p=.000)$, and greater investment $(t=4.893, d f=255, p=.000)$. Whether students felt they managed their studies effectively or not did not matter in terms of overall level of commitment, but it did matter in terms of the meaningfulness of their commitment $(t=3.447, d f=247, p=.001)$. Using a one-way analysis of variance with the Scheffé as a post hoc test to control for Type I error, results indicated that students who reported spending more than $120 \mathrm{~min}$ per day on their studies reported significantly higher investment in their studies $(F=24.504, p=.000)$, as well as higher overall level of commitment $(F=3.803, p=.024)$, but no significant differences were observed for meaningfulness of commitments.

\section{Discussion}

The present study contributes to the literature on the risk factors associated with high drop-out rates reported for South African higher education institutions (Strydom et al., 2012), and the developing 
literature on academic commitment (Human-Vogel, 2008, 2013) by considering what meaningful commitment constitutes.

Our results indicate that students' overall level of commitment can be robustly predicted by the extent to which students feel satisfied with their studies, and a clear and stable sense of self, as indicated by their level of self-differentiation (Skowron \& Friedlander, 1998). Those with a higher level of self-differentiation also tend to report that they feel supported by their families in their studies, which is consistent with Skowron, Wester, and Azen's (2004) findings that the maintenance of positive ties with one's family is supportive of greater self-differentiation and autonomy. To the extent that the high drop-out rate among higher education students are partially explained by the transition to higher education (Raines and Lewandowski, 2009), our results indicate a stable sense of self and the family support associated with it may matter in terms of the extent to which students adjust to the stresses of their studies (Skowron et al., 2004) because they predict the extent to which students will persist with their studies. That meaningful commitment can be predicted by satisfaction, quality of alternatives and investment offers indirect support for the relevance of identity-related commitment to academic success in higher education (Human-Vogel, 2008). In addition, researchers have demonstrated that self-differentiation predicts effortful control (Skowron \& Dendy, 2004), and the present study further supports the notion that those students who have a clear sense of self, who are less emotionally reactive, and have a well-established sense of autonomy are possibly better able to focus their self-regulatory behaviours on attaining goals consistent with their commitment by investing their resources appropriately. Two of the three bases of commitment in the investment model of commitment (Rusbult et al., 1998) that we adapted to measure commitment in an academic context, namely quality of alternatives and investment, did not predict level of commitment, but did predict meaningful commitment. For quality of alternatives, the results point to the fact that it was a significantly shorter scale (only three items), and therefore, it is unlikely that the construct was measured properly. The high drop-out rate at universities countrywide would suggest that students do perceive favourable alternatives to studying, but we think our results point to the fact that when students drop out of their studies, it is probably not because they would rather do something other than studying, but perhaps because of other external factors, such as lack of resources. It was more surprising that students' investments did not predict level of commitment significantly, as we expected that a strong level of commitment would be associated with the tendency to invest more in one's studies. Investment, along with satisfaction, certainly mattered when it came to setting learning goals, managing their studies, or the amount of time students spent on their studies. At least two tempting conclusions can be drawn from these results. One is that how students approach their studies may be consistent with the size of the investments they make, or the satisfaction they report, but whether they are committed, that is, their determination and persistence to complete their studies is certainly not related to the amount of effort they invest. This point of view would provide supportive evidence of our conceptualisation of level of commitment as distinct from student engagement, which is reported in the literature to be clearly related with academic success (Krause \& Coates, 2008). Also, the investments students make in their studies may simply reflect the fact that they are obligated to complete their degrees (reflecting goal commitment), but it may not be indicative of meaningful commitment. In the present study, level of commitment reflected the determination to persist and complete one's studies. The question can now be asked whether determination to complete one's studies is actually predictive of academic success. We have demonstrated that satisfaction and self-differentiation are significant predictors of commitment level, but only satisfaction turned out to be relevant in terms of whether students set learning goals or how they manage their studies. A notable and significant limitation of the present study that would have helped to clarify this question is that we were unable to collect data on participants' academic achievement scores. In the absence of such data, we can only conjecture that 
what our data may be suggesting is that students may enter university highly committed to the goal of completing their studies, but that this goal commitment does not necessarily reflect identity-relevant, meaningful commitment. Some support for this argument comes from the regression model in which we regressed satisfaction, quality of alternatives, investment, and selfdifferentiation on meaningful commitment. Meaningful commitment was operationalised to reflect identity-level commitment, and not simply persistence to complete one's studies. The more students report satisfaction with their studies, a lack of quality alternatives, greater investment, and higher self-differentiation, the more likely they were to experience meaningful commitment. We believe these results offer tentative support for a framework in which identity-level commitments are conceptualised as distinct from goal and task commitments (Lord et al., 2010). We further suggest that level of commitment (implying long-term persistence and intention to complete studies) is not reflective of an identity-level commitment, but is more associated with goal commitment.

Recent meta-analyses of the psychological correlates of university students' academic performance indicated that some of the strongest correlates of academic achievement at university are effort-regulation and academic self-efficacy, with performance self-efficacy emerging as the strongest correlate (Richardson, Abraham, \& Bond, 2012). In terms of the present study, it seems how students think about their performance, and whether they feel they can perform academically is likely to be a very strong moderator of their commitment. How students think about their performance reflects cognitive schemas about personal performance on the task level of self-regulation, and we think it will be influenced and constrained by identity-level commitments on a higher level. Thus, future research must first of all examine how the various levels of academic commitment predict academic achievement, while taking into account the moderating effects of effortful control and academic self-efficacy. Of course, given the role of many other external and environmental factors related to the study environment, study finance, and availability of resources for studying, one must distinguish between predicting academic achievement and predicting the likelihood to complete one's studies. Some of the stressors that students experience and that may contribute to early departure from university include financial difficulties, problems with education, and fear of failing (Pillay \& Ngcobo, 2010). Thus, future studies on academic commitment should control for the effect of external, non-psychological variables to improve understanding of the role of academic commitment in academic achievement, and also draw samples that will be more representative of students in all years of study. For example, it is possible that students' self-differentiation scores may change as they mature, so that the extent to which self-differentiation predicts meaningful academic commitment may be different for final year students as opposed to first or second year students.

In the present study, we sought to examine the factors associated with academic commitment and sought to illuminate the role of identity in academic commitment. We found that satisfaction and self-differentiation are significant predictors of level of academic commitment, whereas meaningful, identity-relevant commitment was more accurately predicted by satisfaction, quality of alternatives, investment, and to a lesser extent, self-differentiation. With more than half of university students in South Africa not completing their university studies, the present study contributes to the literature by demonstrating the importance of helping students to develop meaningful, identity-level commitments. This may be accomplished by the way in which parents, teachers, and learning institutions facilitate the development of a clear and stable sense of self. Our results also suggest how important it is for students to experience commitment as meaningful - that is, personally relevant - and to be content with their studies and to feel fulfilled by their study choices.

\section{Funding}

This research received no specific grant from any funding agency in the public, commercial, or not-for-profit sectors. 


\section{References}

Bjork, R. A., Dunlosky, J., \& Kornell, N. (2013). Self-regulated learning: Beliefs, techniques and illusions. Annual Review of Psychology, 64, 417-444.

Council on Higher Education. (2013). Vital stats. Pretoria, South Africa: Author.

De Vellis, R. F. (2012). Scale development: Theory and applications. Los Angeles, CA: SAGE.

Deci, E. L., \& Ryan, R. M. (2008). Hedonia, eudaimonia, and wellbeing: An introduction. Journal of Happiness Studies, 9, 1-11.

Finn, J. D., \& Zimmer, K. S. (2012). Student engagement: What is it? Why does it matter? In S. L. Christenson, A. L. Reschly \& C. Wylie (Eds.), Research on student engagement (pp. 97-131). New York, NY: Springer.

Geyer, P. D., Brannon, Y. S., \& Shearon, R. W. (1987). The prediction of students' satisfaction with community college vocational training. Journal of Psychology, 121, 591-597.

Human-Vogel, S. (2008). The role of identity in self-regulation: When do students cope and when do they commit? Journal of Psychology in Africa, 18, 115-122.

Human-Vogel, S. (2013). A self-regulatory perspective of commitment in academic and interpersonal contexts. In M. P. Wissing (Ed.), Well-being Research in South Africa (pp. 517-538). Dordrecht, The Netherlands: Springer.

Kluger, A. N., \& Koslowsky, M. (1988). Commitment and academic success. Social Behavior and Personality, $16,121-125$.

Krause, K. L., \& Coates, H. (2008). Students' engagement in first-year university. Assessment \& Evaluation in Higher Education, 33, 493-505.

Le, B., \& Agnew, C. R. (2003). Commitment and its theorized determinants: A meta-analysis of the investment model. Personal Relationships, 10, 37-57.

Lord, R. G., Diefendorff, J. M., Schmidt, A. M., \& Hall, R. J. (2010). Self-regulation at work. Annual Review of Psychology, 61, 543-568.

Mendenhall, W., \& Sincich, T. (2003). A second course in statistics: Regression analysis. Upper Saddle River, NJ: Pearson Education, Inc.

Niemiec, C. P., \& Ryan, R. M. (2009). Autonomy, competence and relatedness in the classroom: Applying self-determination theory to education practice. Theory and Research in Education, 7, 133-144.

Pillay, A. L., \& Ngcobo, H. S. B. (2010). Sources of stress and support among rural-based first-year university students: An exploratory study. South African Journal of Psychology, 40, 234-240.

Raines, A. J., \& Lewandowski, G. (2009). The role of self-views in college adjustment. Graduate Student Journal of Psychology, 11, 46-51.

Richardson, M., Abraham, C., \& Bond, R. (2012). Psychological correlates of university students' academic performance: A systematic review and meta-analysis. Psychological Bulletin, 138, 353-387.

Rusbult, C. E., Martz, J. M., \& Agnew, C. R. (1998). The Investment Model Scale: Measuring commitment level, satisfaction level, quality of alternatives, and investment size. Personal Relationships, 5, 357-391.

Sedikides, C., Gaertner, L., Luke, M. A., O’Mara, E. M., \& Gebauer, J. (2013). A three-tier hierarchy of motivational self-potency: Individual self, relational self, collective self. Advances in Experimental Social Psychology, 48, 235-296.

Skowron, E. A., \& Dendy, A. K. (2004). Differentiation of self and attachment in adulthood: Relational correlates of effortful control. Contemporary Family Therapy, 26, 337-357.

Skowron, E. A., \& Friedlander, M. L. (1998). The Differentiation of self-inventory: Development and initial validation. Journal of Counseling Psychology, 45, 235-246.

Skowron, E. A., Holmes, S. E., \& Sabatelli, R. M. (2003). Deconstructing differentiation: Self-regulation, interdependent relating, and well-being in adulthood. Contemporary Family Therapy, 25, 111-129.

Skowron, E. A., Wester, S. R., \& Azen, R. (2004). Differentiation of self mediates college stress and adjustment. Journal of Counseling and Development, 82, 69-78.

Strydom, J. F., Basson, N., \& Mentz, M. (2012). Enhancing the quality of teaching and learning: Using student engagement data to establish a culture of evidence. Pretoria, South Africa: Council on Higher Education. 


\section{Appendix I}

\section{Academic Commitment Scale}

Level of commitment

1. I want to continue with my studies.

2. I believe in life-long learning.

3. I am determined to complete my studies successfully.

4. I will persist with my studies until I complete my degree.

5. I am not prepared to give up studying.

\section{Satisfaction}

1. My studies give me a great deal of satisfaction.

2. I am very happy with my studies.

3. Being able to study is close to ideal.

4. My studies are fulfilling to me.

5. My studies fulfil my needs for intellectual stimulation and intellectual interaction.

6. I enjoy studying.

7. I feel content with my studies.

8. I feel very involved in my studies - very strongly linked to my studies.

Quality of alternatives

1. If I had a choice, I would rather do something other than study.

2. There are better things in life than studying.

3. Anything else would be better than having to study.

Investment

1. I feel very involved in my studies - like I have put a great deal into it.

2. Compared to others I know, I have invested a great deal of time and effort in my studies.

3. I spend a lot of time on my studies.

4. I usually put a lot of effort into my studies.

5. I do a lot to ensure success in my studies.

\section{Meaningfulness}

1. Being a student allows me to express myself completely.

2. My approach to my studies reflects who I am as a person.

3. My studies contribute to shaping me as a person.

4. I am the kind of person who thrives on studying.

5. My studies fulfil me.

6. Studying is a central aspect of who I am.

7. Studying lends meaning to my life.

8. I express myself through my studies.

9. Studying is an important part of my life. 